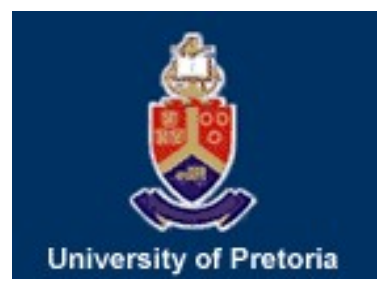

\author{
University of Pretoria \\ Department of Economics Working Paper Series
}

\author{
Effects of Conventional and Unconventional Monetary Policy Shocks on Housing \\ Prices in the United States: The Role of Sentiment \\ Petre Caraiani \\ Romanian Academy \\ Rangan Gupta \\ University of Pretoria \\ Chi Keung Marco Lau \\ University of Huddersfield \\ Hardik A. Marfatia \\ Northeastern Illinois University \\ Working Paper: 2019-53 \\ July 2019
}

Department of Economics

University of Pretoria

0002, Pretoria

South Africa

Tel: +27124202413 


\title{
Effects of Conventional and Unconventional Monetary Policy Shocks on Housing Prices in the United States: The Role of Sentiment
}

\author{
Petre Caraiani", Rangan Gupta**, Chi Keung Marco Lau*** and Hardik A. Marfatia****
}

\begin{abstract}
In this paper, we use a Quantile Structural Vector Autoregressive (QSVAR) model, estimated over the quarterly period of 1975:Q3 to 2017:Q3, to analyze whether the impact of monetary policy shocks on real housing returns in the United States is contingent on the initial state of housing market sentiment. We find that contractionary monetary policy reduces real housing returns more strongly when the market is characterized by optimism rather than pessimism, with this effect being more pronounced under unconventional monetary policy decisions. Further robustness checks confirm our results. Our findings highlight the role in sentiments in driving the policy effectiveness and thus, have important implications for policy decisions.
\end{abstract}

Keywords: House price; Monetary policy; Housing sentiment; Quantile Structural Vector Autoregressive Model.

JEL Codes: C32; R31.

\footnotetext{
${ }^{*}$ Institute for Economic Forecasting, Romanian Academy, 050711, Bucharest - Romania, Casa Academiei, Calea 13 Septembrie nr.13, Sector 5. Email: caraiani@ipe.ro.

** Corresponding author. Department of Economics, University of Pretoria, Pretoria, 0002, South Africa. Email: rangan.gupta@up.ac.za.

${ }^{* * *}$ Department of Economics, Northeastern Illinois University, BBH 344G, 5500 N. St. Louis Ave., Chicago, IL 60625, USA. E-mail: h-marfatia@neiu.edu.

**** Department of Accountancy, Finance and Economics, Huddersfield Business School, University of Huddersfield, Queensgate, Huddersfield, HD1 3DH, UK. Email: $\underline{\text { C.Lau@,hud.ac.uk. }}$
} 


\section{Introduction}

The rapid decline of housing prices in the United States (US) following a prolonged boom is commonly associated as the main underlying reason for the "Great Recession" and the global economic and financial crisis of 2008-2009 (Leamer, 2015; Nyakabawo et al., 2015; Emirmahmutoglu et al., 2016). In this regard, a growing number of studies have analysed the impact of unconventional monetary policy in reviving the housing (real estate) market (Claus et al., 2014, 2016; Rahal, 2016; Gupta and Marfatia, 2018; Huber and Punzi, 2018; Nyakabawo et al., 2018; Gupta et al., 2019a; André et al., 2018, Fischer et al., 2019; Caraiani et al., forthcoming; Paul, forthcoming). Also, there is exceptionally large literature on the role of (conventional) monetary policy shocks in driving the historical growth in housing (real estate) prices of the US based on wide-variety of (linear and nonlinear) frameworks (see, SimoKengne et al., (2016), Marfatia et al., (2017), Plakandaras et al., (2018), and Ume (2018) for detailed reviews of this literature). ${ }^{1}$ In general, these studies tend to suggest that a contractionary monetary policy reduces (nominal or real) housing prices and/or returns.

Against this backdrop, the objective of this paper is to analyze the impact of (conventional and unconventional) monetary policy on housing prices, by analysing, for the first time, the strength of transmission of such shocks conditional on housing market sentiment, using a Quantile Structural Vector Autoregressive (QSVAR) model. ${ }^{2}$ By conditioning our analysis on various quantiles of housing sentiment, we are able to capture the impact of monetary policy shocks on housing prices using regime-specific impulse response functions. We use the measure of housing sentiment developed by Bork et al., (forthcoming) which is based on household responses to questions regarding house buying conditions. In addition, with our analysis covering the quarterly period of 1975:Q3 to 2017:Q3 which include the zero lower bound (ZLB) situation in the US, we are able to study the impact of both conventional and unconventional monetary policies on house price behaviour using the same metric of monetary policy decisions. We use the shadow policy rate obtained from the three-factor shadow rate term structure model (SRTSM) of Wu and Xia (2016). Wu and Xia (2016) have shown that such a model offers an excellent description of the historical behaviour of the Federal funds rate and can be used to summarize the macroeconomic effects of both conventional and unconventional monetary policies. Note that, besides analysing the general impact of monetary policy shocks on house prices under various levels of sentiment, we can also differentiate between the impact of unconventional monetary policy shock from its conventional counterpart in our QSVAR by additionally (i.e., besides the sentiment) conditioning the shadow policy rate at a lower quantile, rather than its median.

The main contribution of our study is that it sheds new light on the behavioural channel associated with the transmission mechanism of monetary policy to housing prices. In this regard, our hypothesis is that the reaction of housing prices is likely to be stronger in periods of high sentiment (upper quantiles), compared to that under low sentiment (lower quantiles). Intuitively, borrowing from the stock market literature (see for example, De Long et al., (1990), and Lee et al., (1991)), the build-up of optimism when sentiment is on the rise leads to an extended period of market overvaluation (due overestimation of the size of rental growth or

\footnotetext{
${ }^{1}$ In this regard the most important studies are that of Baffoe-Bonnie (1998), Fratantoni and Schuh (2003), Del Negro and Otrok (2007), Iacoviello and Minetti (2008), Jarocinski and Smets (2008), Vargas-Silva (2008), Beltratti and Morana (2010), Demary (2010), Chang et al., (2011), Moench and Ng (2011), Musso et al., (2011), Bjørnland and Jacobsen (2013), Chou and Chen (2014), Jordà et al., (2015).

${ }^{2}$ Note that, our decision to use the QSVAR model over Markov-switching or smooth transition approaches is motivated out of the advantages the QSVAR possesses over these standard nonlinear models in terms of ex ante classification of different regimes and specification of parametric transition function respectively. By contrast, the QSVAR used here allow us to estimate the impact of monetary policy shocks on the whole conditional distribution of all the variables in the model with parameters being allowed to vary across different quantiles without constraints. The reader is referred to Gupta et al., (2019b) for a detailed discussion in this regard.
} 
underestimation of risks), with house prices departing further from its fundamentals. Hence a contractionary monetary policy shock during this period is likely to produce a relatively strong correction back to equilibrium than when sentiment is relatively low. The remainder of the paper is organized as follows: Section 2 presents the data; Section 3 outlines the methodology; Section 4 discusses the results, and Section 5 concludes.

\section{Data}

Our dataset comprises of four variables - real Gross Domestic Product (GDP), real house price, real interest rate, and housing market sentiment - over the quarterly period of 1975:Q3 to 2017:Q3, with the start and end date being driven by data availability of the sentiment variable. Seasonally-adjusted real GDP (in billions of chained 2012 dollars) is obtained from the FRED database of the Federal Reserve Bank of St. Louis.For nominal house prices, we seasonallyadjust (using the X-13 method of the US Census Bureau) the all-transactions house price index available from the Federal Housing Finance Agency (FHFA). The FHFA all-transactions index is constructed using repeat-sales and refinancings on the same single-family properties. The nominal house prices are deflated by the seasonally-adjusted consumer house price index (CPI, with the base year of 1982-1984), derived again from the FRED database. As far as the real interest rates are concerned, we subtract the CPI-based annualized inflation rate from the policy rate, which in turn is the estimated shadow rates derived from a three-factor shadow rate term structure model (SRTSM) of Wu and Xia (2016) over the period of 1975:Q3 to 2015:Q4. ${ }^{3}$ For over the remainder of the period (2016:Q1 to 2017:Q3), we use the Federal funds rate obtained from the FRED database, given that the Federal Reserve increased the Federal funds rate by 50 basis points in December 2015, thus coming out of the ZLB-situation formally. Note that since real GDP, house price and the housing sentiment variables are only available quarterly, we use three-month averages of the policy rate and the CPI when generating the real house prices and real interest rates.

Finally, the housing sentiment index is based on the work of Bork et al., (forthcoming). The authors use time series data from the consumer surveys of the University of Michigan, with the definition of the sentiment variable based on the general attitude of households about house buying conditions. The study considers the underlying reasons households to provide their views about all the house buying conditions. The part of University of Michigan's consumer survey related to house buying conditions starts with the question: "Generally speaking, do you think now is a good time or a bad time to buy a house?", with the follow-up question: "Why do you say so?". In constructing the index, Bork et al. (forthcoming) focus on the responses to the follow-up question, since the idea is to draw the information on the underlying reasons why households believe that it is a bad or good time to buy a house. Specifically, the housing sentiment index is based on the following ten time series: good time to buy; prices are low, good time to buy; prices are going higher, good time to buy; interest rates are low, good time to buy; borrow-in-advance of rising interest rates, good time to buy; good investment, good time to buy; times are good, bad time to buy; prices are high, bad time to buy; interest rates are high, bad time to buy; cannot afford, and bad time to buy; uncertain future. Then Bork et al., (forthcoming) used partial least squares (PLS) to aggregate the information contained in each of the ten time series into an easy-to-interpret index of housing sentiment.The PLS filters out idiosyncratic noise from the individual time series and summarizes the most important information in a single index. ${ }^{4}$

3 The data is available for download from the website of Professor Jing Cynthia Wu at:
https://sites.google.com/view/jingcynthiawu/shadow-rates?authuser=1.
4 The data is available for download from the website of Professor Lasse Bork at: https://www.dropbox.com/s/tvdim1s529jbva6/Online\%20data\%20-\%20update\%202017.xlsx?dl=0. 
With the QSVAR approach requiring mean reverting data, we transform the real GDP and real house prices into their respective growth rates, while we use real interest rate and the housing sentiment index in their level-forms. The data has been plotted in Figure A1 in the Appendix of the paper.

\section{Methodology}

As indicated earlier, we use a quantile structural vector autoregressive (QSVAR) model to estimate quantiles-based impulse responses of output growth, housing returns, and housing sentiment following a shock to the real interest rate. We are interested in examining these dynamic responses by conditioning on various quantiles of housing sentiment and real interest rate, which in turn captures the general attitude of households about house buying conditions, and nature (conventional and unconventional) monetary policy respectively.

We start off by laying the basics of quantile regression. We specify the $\tau$-th quantile $(0<\tau<1)$ of the conditional distribution of the vector of dependent variables $y_{t}$ given a vector of independent variables $x_{t}$, as follows:

$Q_{\tau}\left(y_{t} \mid x_{t}\right)=x_{t} \beta(\tau)$

where $Q_{\tau}\left(y_{t}\right)=F^{-1}(\tau), F\left(y_{t}\right)$ is the probability distribution function (pdf) of the $y_{t}$. The parameter vector $\beta(\tau)$ quantifies the responses of variables at different quantile $\tau$ of the distribution.

Parameters in equation (1) can be estimated by minimizing the absolute value of the residual using the following objective function:

$Q_{\tau}\left(\beta_{\tau}\right)=\underset{\beta(\tau)}{\operatorname{argmin}} \sum_{i=1}^{T}\left(\tau-1_{\left\{y_{t}<x_{t} \beta(\tau)\right\}}\right)\left|y_{t}-x_{t} \beta(\tau)\right|$

where $1_{\left\{y_{t}<x_{t} \beta(\tau)\right\}}$ is the indicator function, with the solution to the quantile regression model being obtained using the programming algorithm suggested by Koenker and d'Orey (1987).

Building on the quantile regression framework, we can specify the reduced form VAR for $\tau^{\text {th }}$ quantile as follows, where the predictors are the lagged values of all the endogenous variables of the model:

$y_{t}=c(\tau)+\sum_{i=1}^{p} \mathrm{~B}_{i}(\tau) y_{t-i}+\mu_{t}(\tau) \quad$ for $t=1, \ldots, T$

where $y_{t}=\left[\begin{array}{c}G R G D P \\ R H R \\ R I R \\ \text { SENTIMENT }\end{array}\right] ; \quad c(\tau)=\left[\begin{array}{c}c_{1}\left(\tau_{1}\right) \\ c_{2}\left(\tau_{2}\right) \\ c_{3}\left(\tau_{3}\right) \\ c_{4}\left(\tau_{4}\right)\end{array}\right] ; \quad \mu_{t}(\tau)=\left[\begin{array}{c}\mu_{t}^{G R G D P}\left(\tau_{1}\right) \\ \mu_{t}^{R H R}\left(\tau_{2}\right) \\ \mu_{t}^{R I R}\left(\tau_{3}\right) \\ \mu_{t}^{S E N T I M E N T}\left(\tau_{4}\right)\end{array}\right]$; and

$$
B_{i}(\tau)=\left(\begin{array}{llll}
B_{i, 11}\left(\tau_{1}\right) & B_{i, 12}\left(\tau_{1}\right) & B_{i, 13}\left(\tau_{1}\right) & B_{i, 14}\left(\tau_{1}\right) \\
B_{i, 21}\left(\tau_{2}\right) & B_{i, 22}\left(\tau_{2}\right) & B_{i, 23}\left(\tau_{2}\right) & B_{i, 24}\left(\tau_{2}\right) \\
B_{i, 31}\left(\tau_{3}\right) & B_{i, 32}\left(\tau_{3}\right) & B_{i, 33}\left(\tau_{3}\right) & B_{i, 34}\left(\tau_{3}\right) \\
B_{i, 41}\left(\tau_{4}\right) & B_{i, 42}\left(\tau_{4}\right) & B_{i, 43}\left(\tau_{4}\right) & B_{i, 44}\left(\tau_{4}\right)
\end{array}\right)
$$

where $y_{t}$ is a $4 \times 1$ vector of endogenous variables containing the growth rate of the real GDP $(G R G D P)$, real housing returns $(R H R)$, the monetary policy variable, i.e., the real interest rate $(R I R)$, and housing sentiment (SENTIMENT). $c(\tau)$ is an intercept vector with quantiles $\tau=\left(\tau_{1}\right.$, 
$\left.\tau_{2}, \tau_{3}, \tau_{4}\right), B_{i}(\tau)$ represents a $4 \times 4$ lagged coefficient matrix with quantiles $\tau=\left(\tau_{1}, \tau_{2}, \tau_{3}, \tau_{4}\right)$ with $i=1, \ldots, p$, and the error terms with quantiles $\tau=\left(\tau_{1}, \tau_{2}, \tau_{3}, \tau_{4}\right)$ is denoted by a $4 \times 1$ vector of $\mu_{t}(\tau)$. We use the above model to examine the effect of monetary policy shock on real housing returns, besides growth rate and sentiment, conditional on the various quantiles of the housing sentiment, as well as the real interest rate. The error terms $\mu_{t}(\tau)$ are assumed to follow the restrictions of:

$$
Q_{\tau}\left(\mu_{t}(\tau) \mid y_{t-1, \ldots,} y_{t-p}\right)=0
$$

Combining equations (3) and (4), we obtain the population responses of y at quantiles $\tau=\left(\tau_{1}\right.$, $\left.\tau_{2}, \tau_{3}, \tau_{4}\right)$ such that:

$$
Q_{\tau}\left(\mu_{t}(\tau) \mid y_{t-1, \ldots,} y_{t-p}\right)=c(\tau)+\sum_{i=1}^{p} \mathrm{~B}_{i}(\tau) y_{t-i}
$$

We estimate equation (5) for each quantile $\tau$ using the quantile regression approach of Cecchetti and $\mathrm{Li}(2008)$.

We identify the shocks of the economic variables by imposing structural restrictions on the error term $\mu_{\mathrm{t}}(\tau)$ such that:

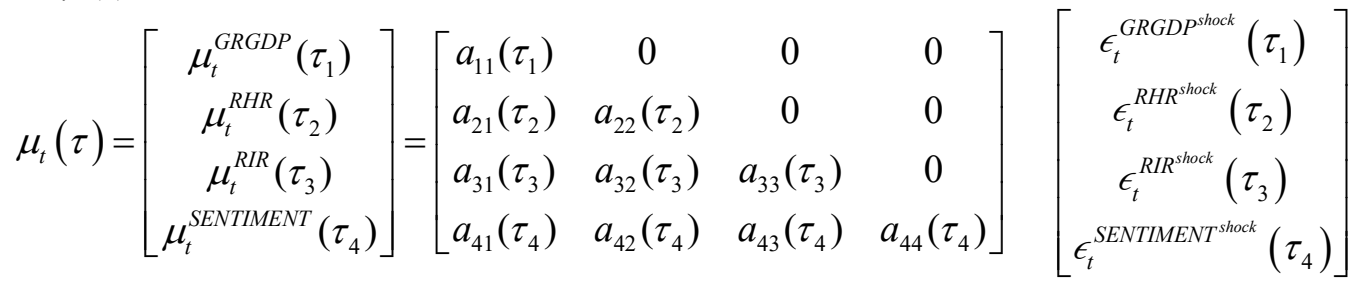

We assume the $\epsilon_{t}$ is a white noise process and employ a standard Cholesky decomposition by imposing a lower triangular matrix. Note that the variables are ordered from most exogenous to least exogenous, with the growth of output first, followed by real housing returns, the real interest rate, and then housing sentiment. This ordering of the real GDP growth and real housing returns in identifying a monetary policy shock follows the extant literature. Both these variables are considered as slowmoving, and hence responds with a lag to the monetary policy shock. However, housing sentiment is considered to be a fast moving variable, and hence reacts contemporaneously to the monetary policy shock, and thus is ordered last in the system.

Once we orthogonalize the covariance matrix of the residuals in equation (6) using a Cholesky decomposition, we calculate the associated quantile-specific impulse response function and obtain the 95 percent confidence interval by using a 'bootstrapping' approach (replicated 5000 times), which involves resampling from the estimated residuals (see, Linnemann and Winkler (2016) for further details). The impulse response plots are used to analyze the effect of a one standard deviation increase in the innovation of the monetary policy variable at time $t$ on another variable at time $t+s$, by conditioning the impulse response functions first on quantiles ( $\tau=0.25$, lower levels of sentiment, and $\tau=0.75$, higher levels of sentiment) of housing sentiment. We then repeat the analysis by now conditioning on a lower quantile of the real interest rate $(\tau=0.25)$, thus capturing unconventional monetary policy. As can be seen from Figure A1, the lower quantiles clearly correspond to the negative real interest rates during the ZLB situation in the US. We use the Schwarz information criterion (SIC) to select the optimal lag order in the QSVAR model and evaluate the impulse response functions over 40 quarters after the shock.

\section{Empirical Analyses}

\subsection{Main Results}

In this sub-section, we analyze the impact of one standard deviation increase in the monetary policy variable, i.e., the real interest rate, on real housing returns in particular (besides real output growth and the housing sentiment), contingent on low $(\tau=0.25)$ and high $(\tau=0.75)$ levels 
of sentiment. Note that we always hold the output growth, real housing returns, and real interest rate to be at their normal mode, i.e., for these variables $\tau$ is at 0.50 . Based on Figure 1, as hypothesized in the introduction, when housing sentiment is relatively higher, a contractionary monetary policy shock has a stronger significant (see Figures A2(a)-A2(b) in the Appendix for the figures with $95 \%$ confidence bands) negative impact on real housing returns, by 0.11 percent relative to 0.10 percent, around the $6^{\text {th }}$ quarter. ${ }^{5,6}$ We also observe that housing sentiment is significantly negatively affected at its upper quantile, but there is an "output puzzle" (Walsh, 2017) initially, and then output goes down after a couple of years, though the effect is not statistically significant.

\section{[INSERT FIGURE 1 HERE]}

In Figure 2, we conduct the same analysis, but now under a lower quantile $(\tau=0.25)$ of the real interest rate variable, with an aim to distinguish between unconventional and conventional (reported in Figure 1, with $\tau=0.50$ for the real interest rate) monetary policy episodes. As can be seen from Figure 2 (and also from Figures A3(a)-A3(b) in the Appendix with 95\% confidence bands), our basic result that monetary policy has a stronger impact on real housing returns when the sentiments are high continues to hold (with the effects being 0.16 percent relative to 0.13 percent), but more strongly under the unconventional regime of monetary policy decisions. Specifically, we observe that under the unconventional monetary policy regime, the difference between the impact on real housing returns under high- and low-levels of sentiment is relatively higher than under the conventional regime, which is due to a similar movements in the housing sentiment variable across the two monetary policy regimes. ${ }^{7}$

\section{[INSERT FIGURE 2 HERE]}

In sum, when the interest rate is at its normal mode, further increases in interest rate does not necessarily reduce housing returns more sharply under optimism, compared to the case when the interest rate is increased from its (initial) low levels, i.e., during the unconventional phase of monetary policy. Interestingly, the state of market sentiments in driving the nature of housing market response to monetary policy shocks corroborates with the behavior of financial assets, where financial risk and uncertainty drives the time-varying response of stock returns (Marfatia, 2014) and bond returns (Marfatia, 2015) to monetary policy shocks.

\footnotetext{
${ }^{5}$ As can be seen from Figures A3(a)-A3(b) in the Appendix, this general conclusion continues to hold irrespective of whether the housing returns is in its bear $(\tau=0.25)$ or bull $(\tau=0.75)$ phases.

${ }^{6}$ Since both the shadow policy rate and the CPI-based inflation rate can be computed monthly, we conduct a an impulse response analysis based on a mixed-frequency VAR model, with real interest rate ordered first (see, Motegi and Sadahiro (2018) for details). Since, there is no quantile version of this model available, we use the unconditional distribution of the sentiment index to determine the values less than equal to the quantile 0.25 and greater than equal to the quantile 0.75 , and then use it as measures of low and high sentiments respectively in the model. As can be seen from the results reported in Figure A4 in the Appendix, while there is indeed a "house price puzzle" (Gupta and Kabundi, 2010; Gupta et al., 2012a, b), we do find weak evidence of contractionary monetary policy reducing real housing returns more strongly at higher sentiments, especially for shocks corresponding to the first two months of a quarter.

${ }^{7} \mathrm{We}$ also repeated the analysis with $\tau=0.75$ of the real interest rate. As can be seen from Figure A6 in the Appendix, the stronger negative impact is observed at the lower value of sentiment, but the negative impact is more prolonged (i.e., slower recovery is observed) under more optimistic scenarios related to housing market decisions. The varied impact on the real housing returns under conventional and unconventional monetary policy under the different sentiment regimes is due to the corresponding behaviour of the housing sentiment following a monetary policy shock. We observed that (not reported formally, but available upon request from the authors), when interest rates are already high, as is sentiment, a contractionary monetary policy has a delayed but prolonged impact on sentiment, which in turn is mirrored by the real housing returns.
} 


\subsection{Robustness Tests}

In this sub-section, we conduct three additional analyses:

(i) We repeated the analysis with $\tau=0.75$ of the real interest rate. As can be seen from Figure A4 in the Appendix, the stronger negative impact is observed when the sentiment is low, but the negative impact is more prolonged (i.e., slower recovery is observed) under more optimistic scenarios of the housing market. The varied impact on the real housing returns under conventional and unconventional monetary policy under the different sentiment regimes is due to the corresponding behavior of the housing sentiment following a monetary policy shock. We observe that when interest rates are already high, as is sentiment, a contractionary monetary policy has a delayed but prolonged impact on sentiment, which in turn is mirrored by the real housing returns.

(ii) We then re-conduct the impact of monetary policy shocks on real housing returns, contingent on low and highlevels of sentiment, with an additional focus on bear and bull-regimes of the housing market. In other words, we condition the impact of the shocks on lower and higher quantiles of real housing returns. As can be seen from Figures A5(a)-A5(b) in the Appendix, the general conclusion continues to hold irrespective of whether the housing returns is in its bear $(\tau=0.25)$ or bull $(\tau=0.75)$ phases, but the contractionary impact is stronger under higher sentiment in the latter case, i.e., when the housing market is generally booming.

(iii) Finally, since both the shadow policy rate and the CPI-based inflation rate can be computed monthly, we conduct an impulse response analysis based on a mixedfrequency VAR model, with real interest rate ordered first (see, Motegi and Sadahiro (2018) for details). Since there is no quantile version of this model available, we use the unconditional distribution of the sentiment index to categorize the values less than equal to the quantile 0.25 and greater than equal to the quantile 0.75 , and then use it as measures of low and high sentiment regimes respectively in the model. As can be seen from the results reported in Figure A6 in the Appendix, while there is indeed a "house price puzzle" (see for example, Gupta and Kabundi (2010), and Gupta et al., (2012a, b) for detailed discussion in this regard), we do find weak evidence of contractionary monetary policy reducing real housing returns more strongly at higher sentiment levels, especially for shocks corresponding to the first two months of a quarter.

Overall, our result that contractionary monetary policy reduces real housing returns more strongly under higher values of sentiment than at lower values. This result holds under alternative robustness test associated with regimes of interest rate, housing returns itself, and to some extent also under mixed frequency.

\section{Concluding Remarks}

Building on the large literature that exists on the impact of (conventional and unconventional) monetary policy shocks on house prices, in this paper we analyze whether the size of this effect depends on whether housing market sentiments are low or high. Using a Quantiles-based Structural Vector Autoregressive (QSVAR) model estimated over 1975:Q3 to 2017:Q3, we find that contractionary monetary policy reduces US housing returns more strongly when the housing market is characterized by optimism rather than pessimism. And the underlying reason behind this is that monetary policy has a stronger negative impact of housing sentiment, when sentiment is relatively high. In addition, the difference is markedly higher in real housing returns across high and low sentiments when the monetary policy shock itself occurs from 
initial low values of the real interest rate, such as those observed during the unconventional period of monetary policy decisions in the wake of the zero lower bound situation in the US. Our results are largely robust to alternative specifications involving higher initial interest rates, regimes of the housing market, and mixed frequency. Our findings imply that the Federal Reserve can impact the housing market indirectly by also affecting housing market sentiment, besides the traditional channel of affecting the cost of borrowing. Moreover, if the Federal Reserve does want to limit housing market bubbles, they are more likely to achieve this via contractionary monetary policy in an environment when housing market sentiments are high. 


\section{References}

André, C., Caraiani, P., Calin, A.C., Gupta, R. (2018). Can Monetary Policy Lean against Housing Bubbles? University of Pretoria, Department of Economics, Working Paper No. 201877.

Baffoe-Bonnie, J. (1998). The dynamic impact of macroeconomic aggregates on housing prices and stock of houses: a national and regional analysis. The Journal of Real Estate Finance and Economics, 17(2), 179-197.

Beltratti, A., and Morana, C. (2010). International house prices and macroeconomic fluctuations. Journal of Banking \& Finance, 34(3), 533-545.

Bork, L., and Møller, S.V., and Pedersen, T.Q. (Forthcoming). A New Index of Housing Sentiment. Management Science.

Bjørnland, H.C., and Jacobsen, D.H. (2013). House prices and stock prices: Different roles in the U.S. monetary transmission mechanism. Scandinavian Journal of Economics, 115(4), 1084-1106.

Cecchetti, S. and Li, H. (2008). Measuring the Impact of Asset Price Booms Using Quantile Vector Autoregressions. Brandeis University, Department of Economics, Mimeo.

Chang, K.L., Chen, N.K., and Leung, C.K. (2011). Monetary policy, term structure and asset return: Comparing REIT, housing and stock. Journal of Real Estate Finance and Economics, 43(1), 221-257.

Chou, Y.-H., and Chen, Y-.C. (2014). Is the Response of REIT Returns to Monetary Policy Asymmetric? Journal of Real Estate Research, 36(1), 109-136.

De Long, J.B., Shleifer, A., Summers, L.H., and Waldmann, R.J. (1990). Noise trader risk in financial markets. Journal of political Economy, 98(4), 703-738.

Caraiani, P., Calin, A.C., and Gupta, R. (Forthcoming). Monetary Policy and Bubbles in US REITs. International Review of Finance.

Claus, E., Claus, I., and Krippner, L. (2014). Asset markets and monetary policy shocks at the zero lower bound. Reserve Bank of New Zealand Discussion Paper No. DP2014/03.

Claus, E., Claus, I., and Krippner, L. (2016). Monetary policy spillovers across the Pacific when interest rates are at the zero lower bound. Asian Economics Papers 15(3), 1-27.

Del Negro, M., and Otrok, C. (2007). 99 Luftballons: Monetary policy and the house price boom across U.S. states. Journal of Monetary Economics, 54(7), 1962-1985.

Demary, M. (2010). The Interplay between Output, Inflation, Interest Rates and House Prices: International Evidence. Journal of Property Research, 27(1), 1-18.

Emirmahmutoglu, F., Balcilar, M., Apergis, N., Simo-Kengne, B.D., Chang, T., and Gupta, R. (2016). Causal Relationship between Asset Prices and Output in the US: Evidence from StateLevel Panel Granger Causality Test. Regional Studies, 50(10), 1728-1741.

Fischer, M.M., Huber, F., Pfarrhofer, M., and Staufer-Steinnocher, P. (2019). The Dynamic Impact of Monetary Policy on Regional Housing Prices in the United States. Real Estate Economics. DOI: https://doi.org/10.1111/1540-6229.12274.

Fratantoni, M., and Schuh, S. (2003). Monetary policy, housing, and heterogeneous regional markets. Journal of Money, Credit, and Banking, 34(4), 557-589.

Gupta, R., Jurgilas, M., Kabundi, A., and Miller, S. M. (2012a). Monetary Policy and Housing Sector Dynamics in a Large-Scale Bayesian Vector Autoregressive Model. International Journal of Strategic Property Management, 16(1), 1-20.

Gupta, R., and Kabundi, A. (2010). The effect of monetary policy on house price inflation: A factor augmented vector autoregression (FAVAR) approach. Journal of Economic Studies, 37(6), 616-626. 
Gupta, R., Lau, C.K.M, and Wohar, M.E. (2019b). The Impact of US Uncertainty on the Euro Area in Good and Bad Times: Evidence from a Quantile Structural Vector Autoregressive Model. Empirica, 46(2), 353-368.

Gupta, R., Lv, Z., and Wong, W-K. (2019a). Macroeconomic Shocks and Changing Dynamics of the U.S. REITs Sector. Sustainability, 11(10), 2776.

Gupta, R., and Marfatia, H. A. (2018). The Impact of Unconventional Monetary Policy Shocks in the US on Emerging Market REITs: A Qual VAR Approach. Journal of Real Estate Literature, 26(1), 175-188.

Gupta, R., Miller, S. M., van Wyk, D. (2012b). Financial Market Liberalization, Monetary Policy, and Housing Price Dynamics. International Business \& Economics Research Journal, 11(1), 69-82.

Huber, F., and Punzi, M.T. (2018). International Housing Markets, Unconventional Monetary Policy and the Zero Lower Bound. Macroeconomic Dynamics. DOI: https://doi.org/10.1017/S1365100518000494.

Iacoviello, M., and Minetti, R. (2008). The Credit Channel of Monetary Policy: Evidence from the Housing Market. Journal of Macroeconomics, 30(1), 69-96.

Jarocinski, M., and Smets, F. (2008). House prices and the stance of monetary policy. Review, Federal Reserve Bank of St. Louis, July, 339-366.

Jordà, Ò., Schularick, M., and Taylor, A.M. (2015). Betting the house. Journal of International Economics, 96(S1), S2-S18.

Koenker, R.W., and d'Orey, V. (1987). Algorithm AS 229: Computing regression quantiles. Journal of the Royal Statistical Society. Series C (Applied Statistics), 36(3), 383-393.

Leamer, E.E. (2015). Housing really is the business cycle: What survives the lessons of 200809? Journal of Money, Credit and Banking, 47(S1), 43-50

Lee, C., Shleifer, A., and Thaler, R.H. (1991). Investor sentiment and the closed-end fund puzzle. Journal of Finance, 46(1), 75-109.

Linnemann, L., and Winkler, R. (2016). Estimating nonlinear effects of fiscal policy using quantile regression methods. Oxford Economic Papers, 68(4), 1120-1145.

Marfatia, H.A. (2014). Impact of uncertainty on high frequency response of the US stock markets to the Fed's policy surprises. The Quarterly Review of Economics and Finance, 54(3), 382-392.

Marfatia, H.A. (2015). Monetary policy's time-varying impact on the US bond markets: Role of financial stress and risks. The North American Journal of Economics and Finance, 34(1), 103-123.

Marfatia, H.A., Gupta, R., Cakan, E. (2017). The International REITs Time-Varying Response to the U.S. Monetary Policy and Macroeconomic Surprises. North American Journal of Economics and Finance, 42(1), 640-653.

Moench, E., and Ng, S. (2011). A hierarchical factor analysis of U.S. housing market dynamics. The Econometrics Journal, 14(1), C1-C24.

Motegi, K., and Sadahiro, A. (2018). Sluggish private investment in Japan's Lost Decade: Mixed frequency vector autoregression approach. North American Journal of Economics and Finance, 43, 118-128.

Musso, A., Neri, S. and Stracca, L. (2011). Housing, consumption and monetary policy: how different are the US and the Euro area? Journal of Banking and Finance, 35(11), 3019-3041.

Nyakabawo, W., Gupta, R., and Marfatia, H.A. (2018). High Frequency Impact of Monetary Policy and Macroeconomic Surprises on US MSAs, Aggregate US Housing Returns and Asymmetric Volatility. Advances in Decision Sciences, 22(A), 1-26.

Nyakabawo, W. V., Miller, S. M., Balcilar, M., Das, S. and Gupta, R. (2015). Temporal Causality between House Prices and Output in the U.S.: A Bootstrap Rolling-window Approach. North American Journal of Economics and Finance, 33(1), 55-73. 
Paul, P. (Forthcoming). The Time-Varying Effect of Monetary Policy on Asset Prices. Review of Economics \& Statistics.

Plakandaras, V., Gupta, R., Katrakilidis, C., Wohar, M.E. (2018). Time-Varying Role of Macroeconomic Shocks on House Prices in the US and UK: Evidence from Over 150 Years of Data. Empirical Economics. DOI: https://doi.org/10.1007/s00181-018-1581-x.

Rahal, C. (2016). Housing Markets and Unconventional Monetary Policy. Journal of Housing Economics, 32, 67-80.

Simo-Kengne, B.D., Miller, S.M., Gupta, R., Balcilar, M. (2016). Evolution of the Monetary Transmission Mechanism in the US: The Role of Asset Returns. The Journal of Real Estate Finance and Economics 52 (3), 226-243.

Ume, E. (2018). The impact of monetary policy on housing market activity: An assessment using sign restrictions? Economic Modelling, 68, 23-31.

Vargas-Silva, C. (2008). Monetary policy and the US housing market: A VAR analysis imposing sign restrictions. Journal of Macroeconomics, 30(3), 977-990.

Walsh, C.E. (2017). Monetary Theory and Policy. MIT Press, $4^{\text {th }}$ Edition.

Wu, J. C., and Xia, F. D. (2016). Measuring the Macroeconomic Impact of Monetary Policy at the Zero Lower Bound. Journal of Money, Credit and Banking, 48, 2-3, 253-291. 
Figure 1. Impact of (Conventional) Monetary Policy Shock under Low- and High-Levels of Sentiment
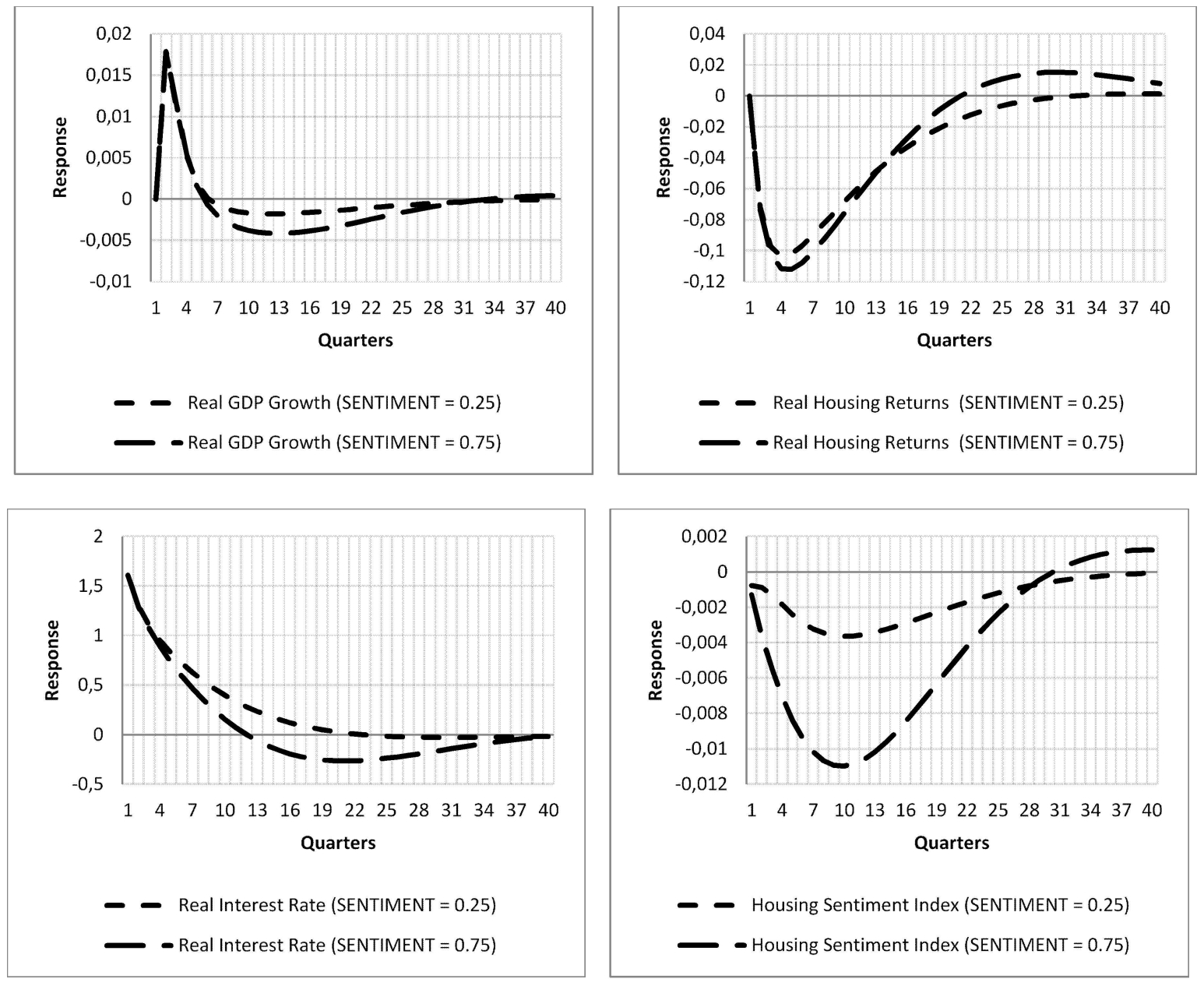
Figure 2. Impact of (Unconventional) Monetary Policy Shock under Low- and High-Levels of Sentiment
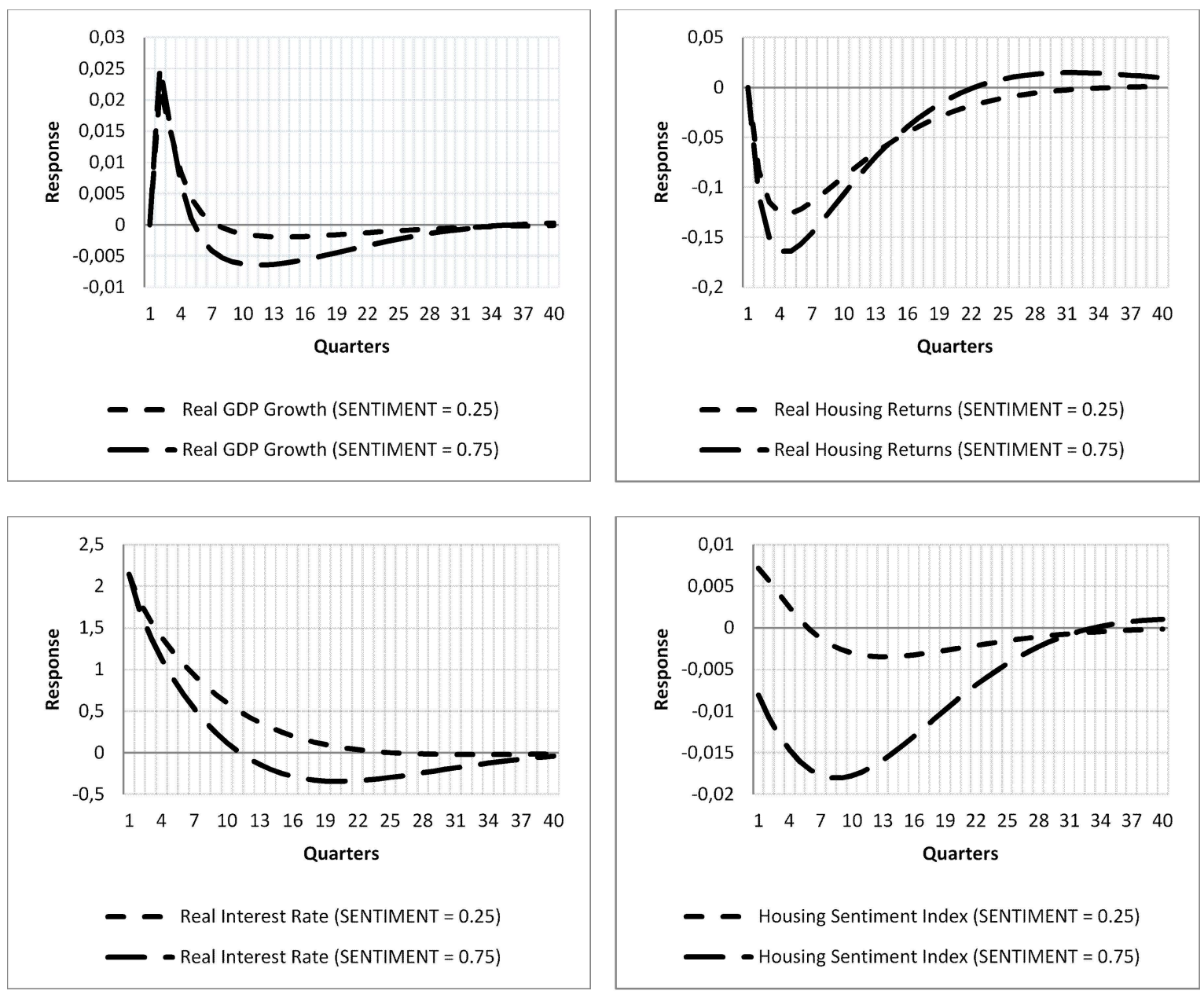
Figure A1. Data Plots

$$
\text { GRGDP }
$$
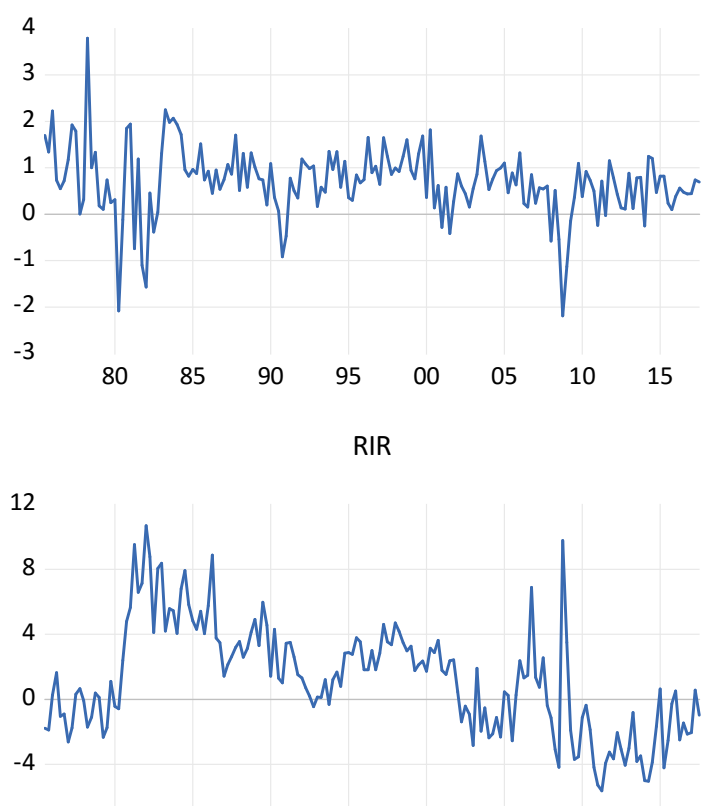

$-8$

\section{APPENDIX}
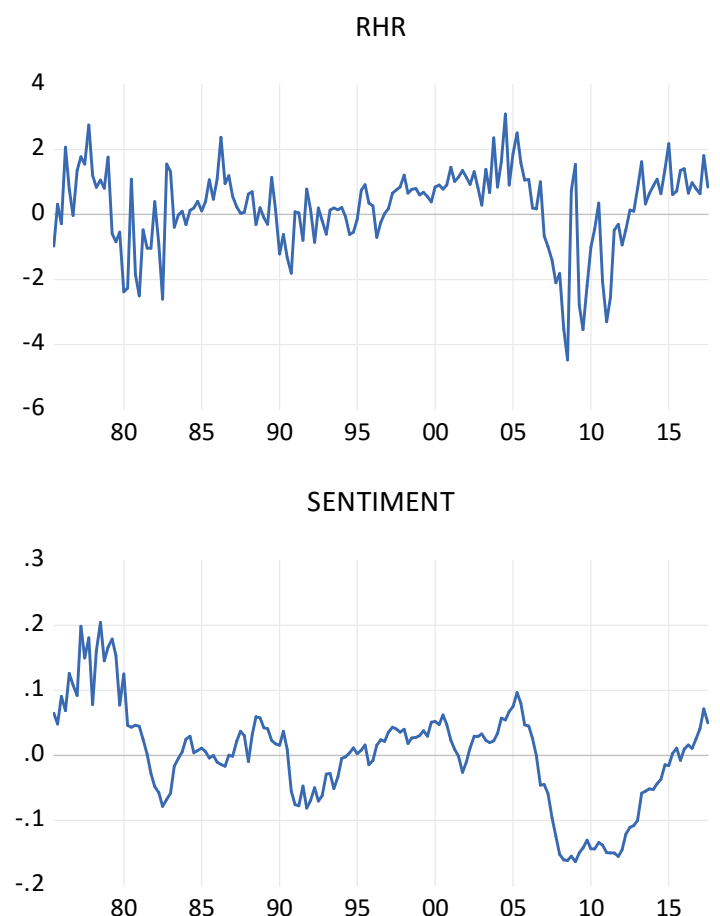

Note: GRGDP: Growth of Real Gross Domestic Product; RHR: Real Housing Returns; RIR: Real Interest Rate; SENTIMENT: Housing Sentiment Index. 
Figure A2(a). Impact of (Conventional) Monetary Policy Shock under Low-Level of Sentiment
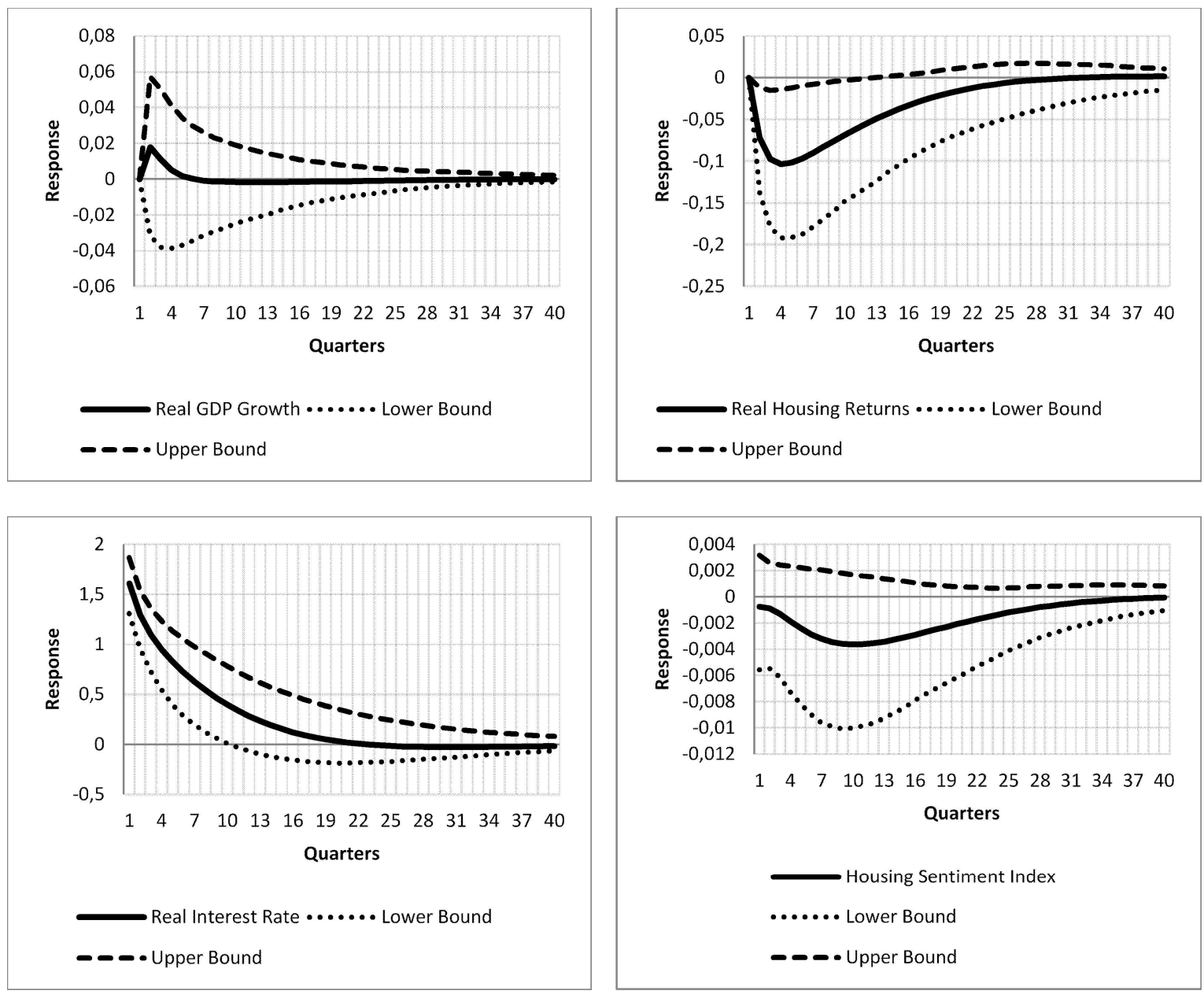
Figure A2(b). Impact of (Conventional) Monetary Policy Shock under High-Level of Sentiment
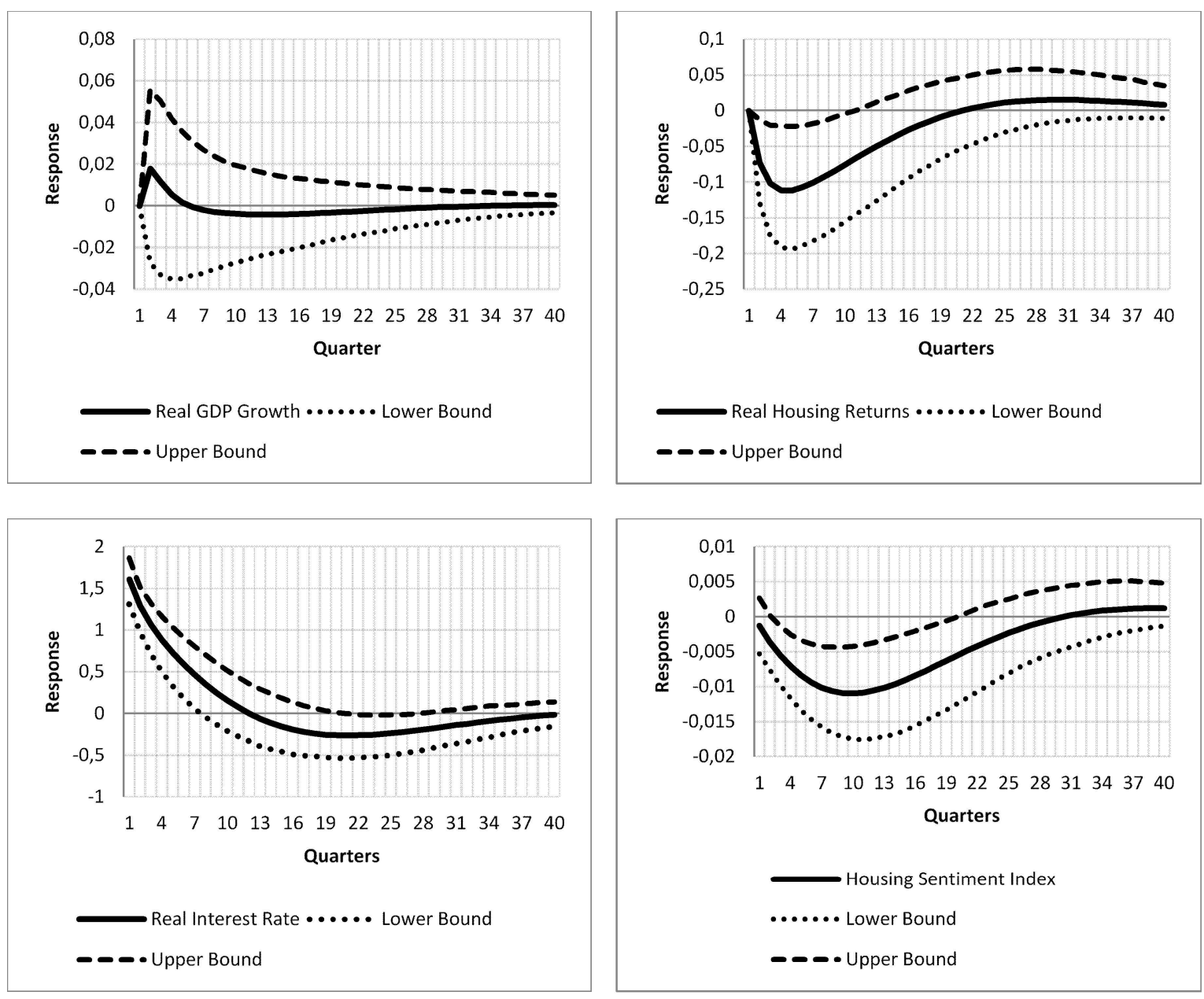
Figure A3(a). Impact of (Unconventional) Monetary Policy Shock under Low-Level of Sentiment
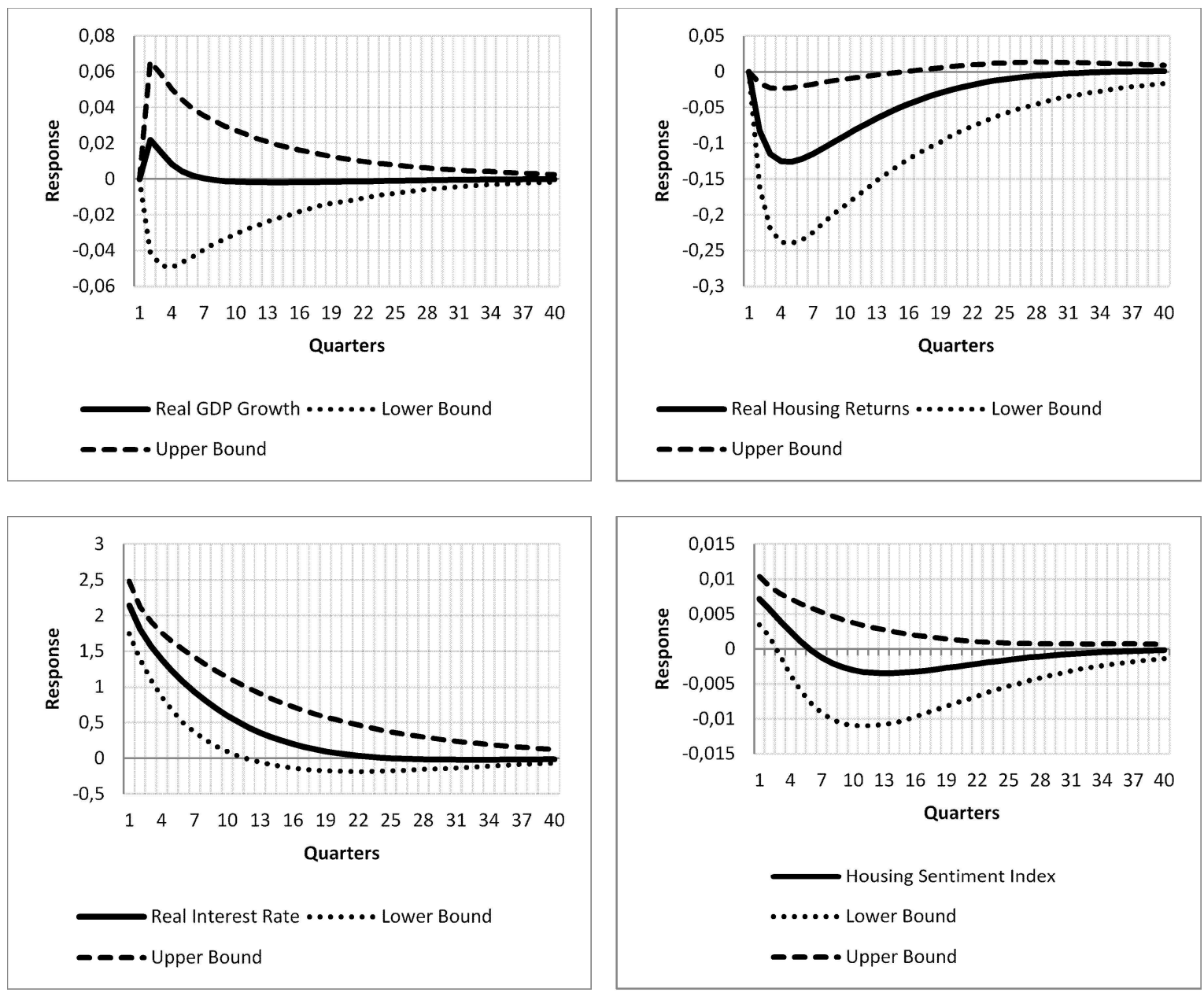
Figure A3(b). Impact of (Unconventional) Monetary Policy Shock under High-Level of Sentiment
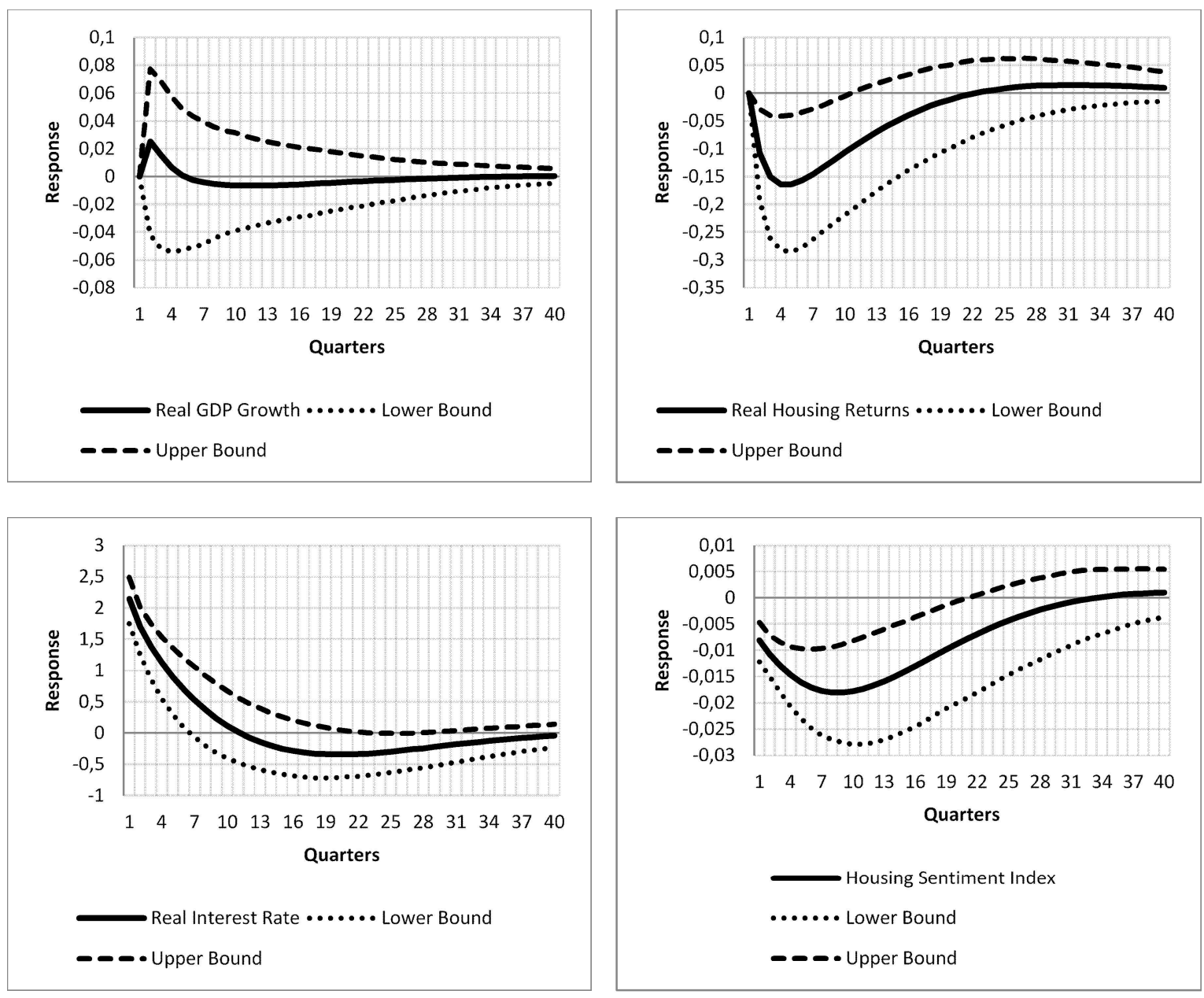
Figure A4. Impact of Monetary Policy Shock at High-Levels of Real Interest Rate under Lowand High-Levels of Sentiment
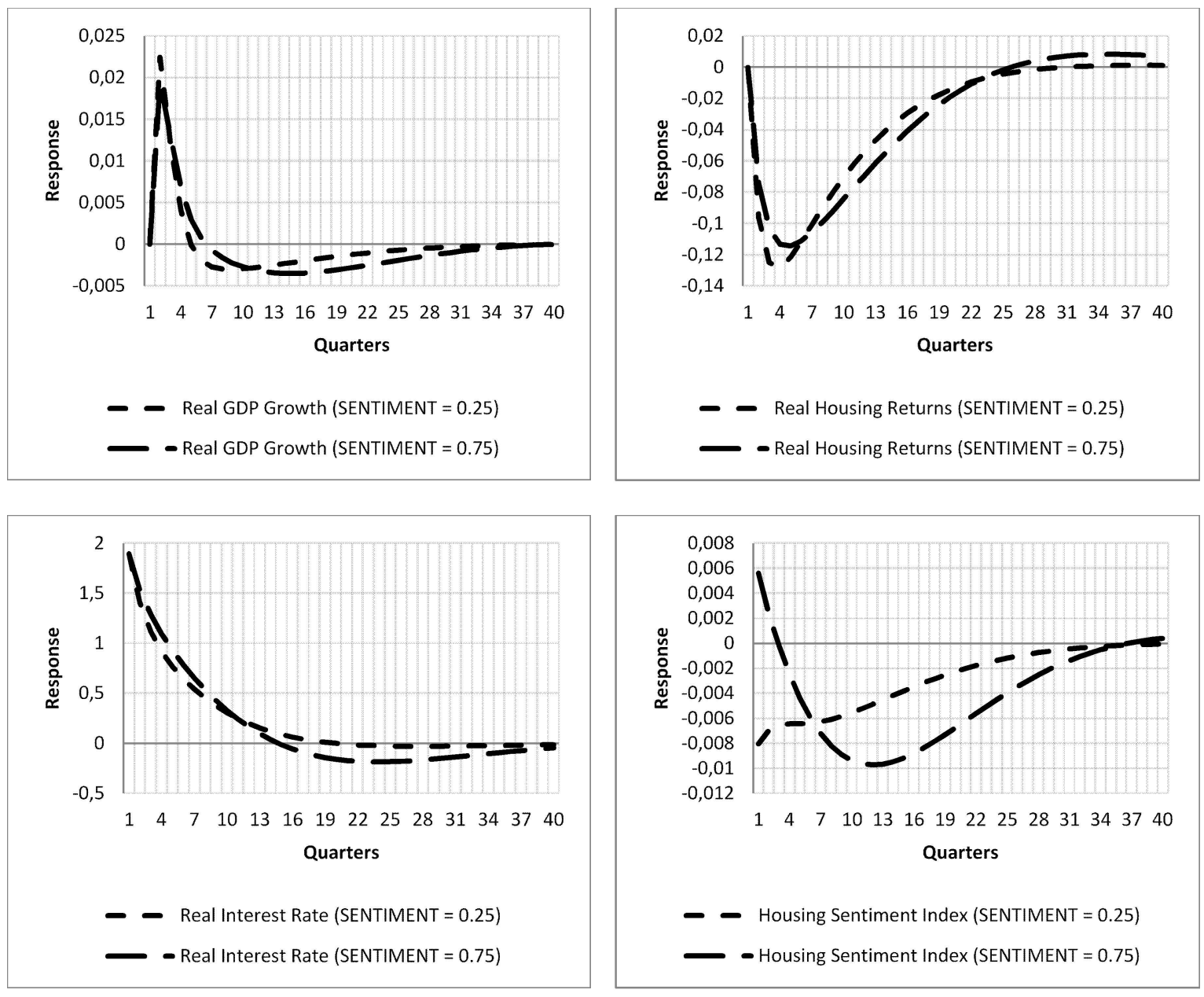
Figure A5(a). Impact of (Conventional) Monetary Policy Shock under Low- and High-Levels of Sentiment and Bearish Housing Market
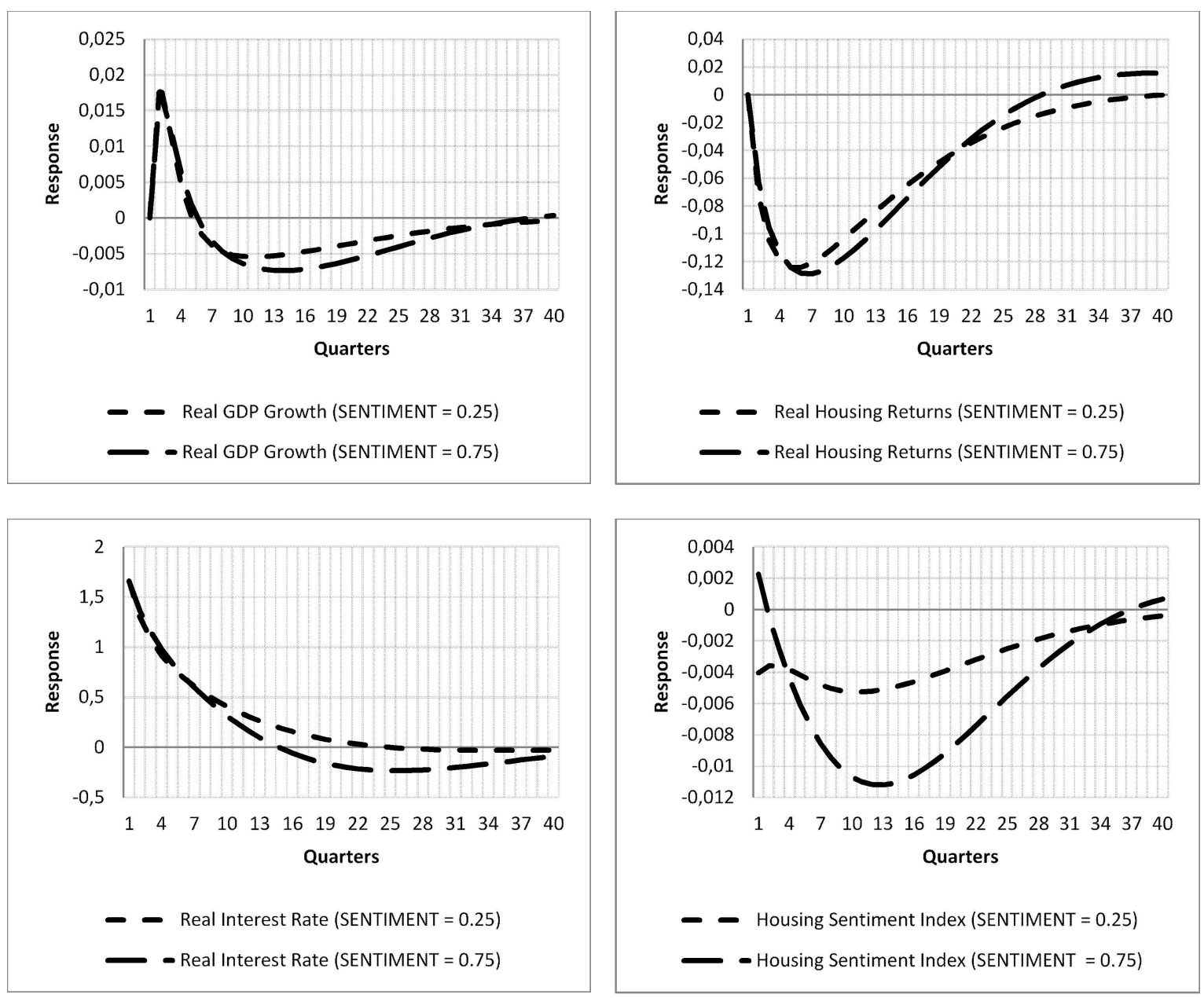
Figure A5(b). Impact of (Conventional) Monetary Policy Shock under Low- and High-Levels of Sentiment and Bullish Housing Market
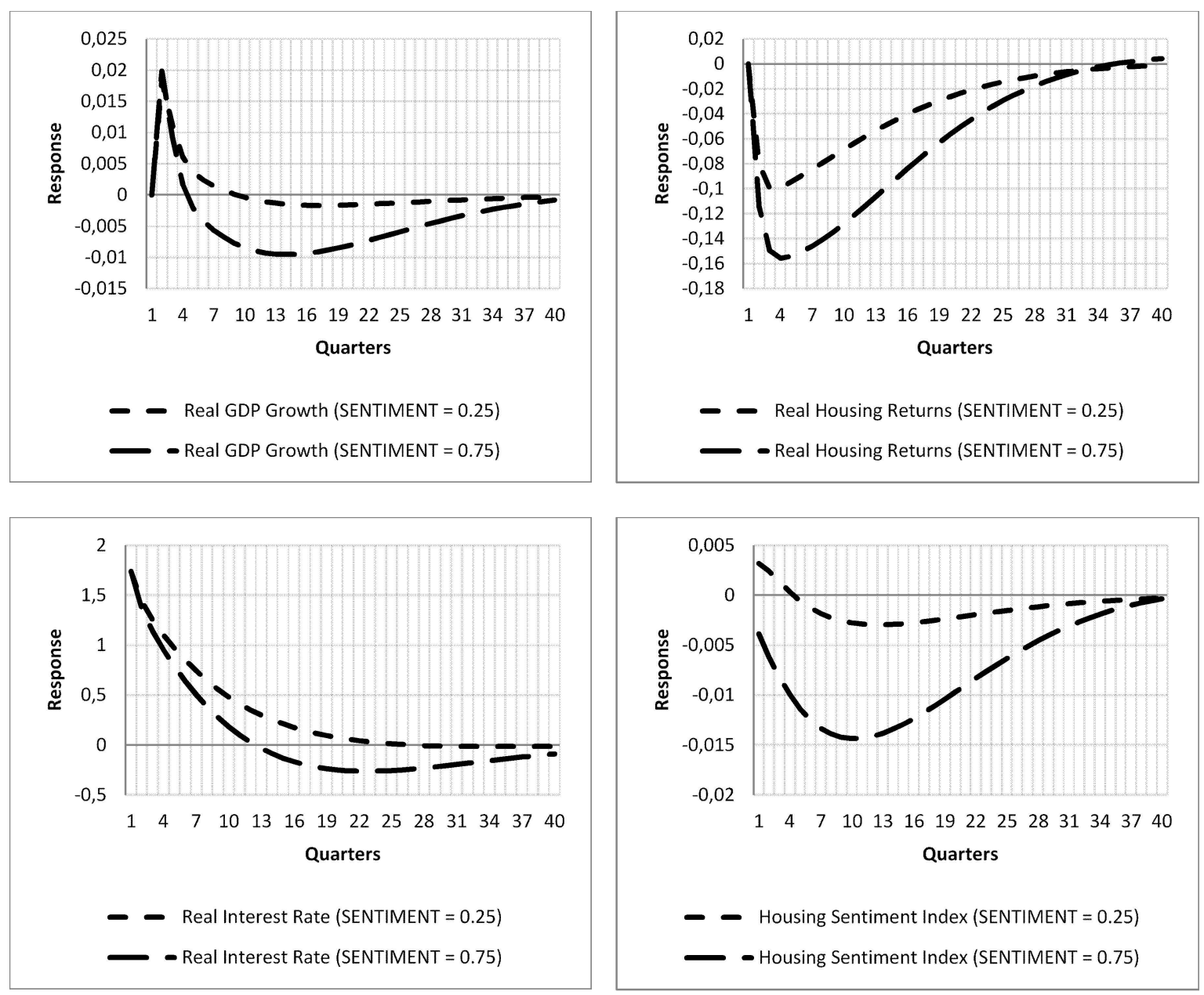
Figure A6. Impact of (Conventional) Monetary Policy Shock under Low- and High-Levels of Sentiment in a Mixed-Frequency VAR
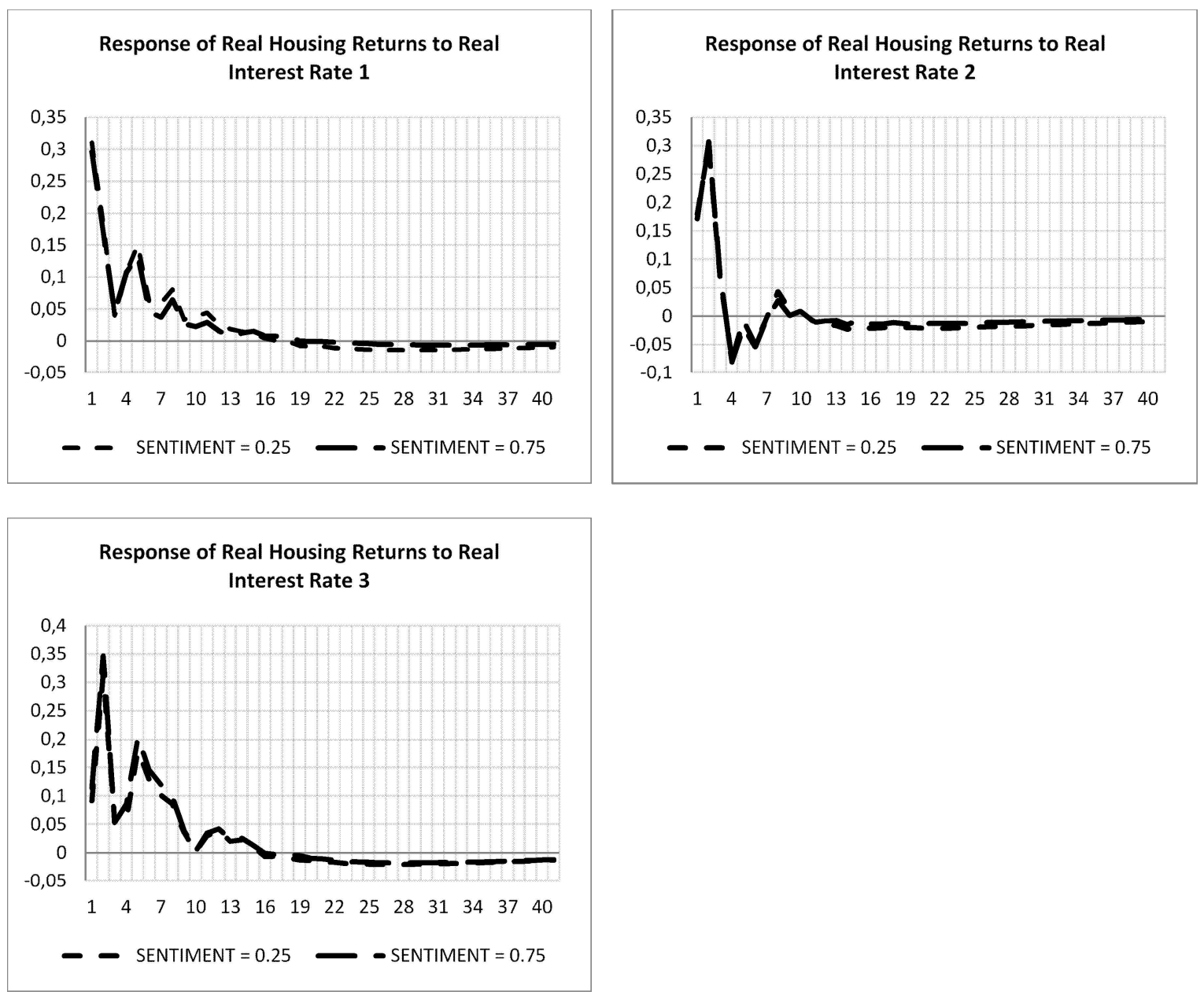

Note: Real Interest Rate 1(2)[3]: Real interest rate for month 1(2)[3] comprising a quarter. 
